\title{
The 61st Conversation: Raising Mental Health Awareness and Resourcefulness through Stories of Strength
}

\author{
Leah Shipton ${ }^{1}$, Bonnie M. Lashewicz ${ }^{1 *}$, Sara Abdelrahim² ${ }^{2}$ and Joy Pavelich ${ }^{3}$ \\ ${ }^{1}$ Community Rehabilitation \& Disability Studies Program, Department of Community Health Sciences, Cumming School of Medicine, University of Calgary \\ ${ }^{2}$ Pursuing High School Diploma \\ ${ }^{3}$ Canadian Mental Health Association, Calgary Region
}

\begin{abstract}
Received: October 14, 2016; Accepted: November 17, 2016; Published: November 22, 2016
*Corresponding author: Bonnie M. Lashewicz, Department of Community Rehabilitation and Disability Studies, Cumming School of Medicine, University of Calgary, 3280 Hospital Drive NW, Calgary, Alberta, T2N 4Z6, Tel: +403-220-4980; Fax: +403-220-6494; E-mail: bmlashew@ucalgary.ca
\end{abstract}

\begin{abstract}
Introduction: Sixty participant stories from the Canadian Mental Health Association Calgary Region "Now I'm Stronger" campaign, designed to drive interest in mental health and addictions, and an additional story shared by the third co-author, were analyzed to inform policy and practice to support people with mental illness and addictions. Participants gave extensive evidence of the hardship of mental illness combined with effort and dedication required to gain strength. Further, participants' detailed ways in which community and societal stakeholders can empower individual efforts and capacity. Recommendations are made for ways mental health stakeholders can understand and respond to community mental health needs.
\end{abstract}

Keywords: Stigma; Mental health; Participatory action research; Mental illness; Community health

\section{Introduction}

Stigma is a societal creation that can be defined as, "the negative regard, inferior status, and relative powerlessness that society collectively accords to people who possess a particular characteristic or belong to a particular group or category" [1,2]. The negative labels and attributes assigned to people with mental illness, such as "violent," "incompetent," and "crazy," carry and perpetuate stigma $[3,4]$. Moreover, stigma becomes part of social structures and institutions maintained by powerful and privileged members of society [5]. Accordingly, members of less powerful, stigmatized groups are prevented from fully participating in, and benefiting from, core spheres of society, such as government, education, justice, and healthcare systems. This exclusion pushes stigmatized groups to the margins of society and allows those who do not experience stigma full participation in society [5], and subsequently their full participation becomes "normalized, naturalized and neutralized"[6]. Stigma is thus at the foundation of interpersonal and systemic prejudice and discrimination and carries detrimental consequences for members of marginalized groups [5,7].

People experience stigma differently depending on their mental illness (e.g. depression, schizophrenia) and whether they are a member of other stigmatized groups such as racial or sexual minorities $[4,5,8]$. Stigma-related stressors include overt life events resulting from stigma such as violence and exclusion from employment and housing, as well as more pervasive and, arguably, less visible, stressors that accompany managing the disclosure of invisible stigmatized identities (e.g. sexual minority, mental illness), managing daily reactions to one's visible stigmatized identities (e.g. racial minority, woman), and internalizing stigma, which occurs when an individual applies negative perceptions of their identity to themselves [5,7]. Corrigan, et al. [7] details the stages of internalized stigma, arguing that an individual with a mental illness, 1) becomes aware of negative public beliefs of their illness, 2) accepts those public beliefs, 3) applies those beliefs to them, and 4) harms and undervalues themselves. Consequently, internalization of a stigmatized identity or identities is associated with decreased self-esteem, self-efficacy, self-worth, quality of life, and increased social isolation $[3,7]$. Further, members of stigmatized groups have poorer mental and physical health outcomes from stigmarelated stressors, difficulties with academic and job opportunities and performance, and experience negative interactions with system-level providers such as healthcare professionals who may hold, and act in accordance with, negative beliefs that lead to compromised quality of care and ultimately may deter decisions by members of stigmatized groups to seek healthcare in the future $[5,8,9]$.

Reducing stigma is difficult, but has potential for positive outcomes for members of stigmatized groups [3]. Stigma is the fault of society as a collective and therefore, responsibility to reduce stigma resides with structural stakeholders, institutions and community organizations [7]. Contact, either in-person or through media platforms, is crucial to population-wide or targeted anti-stigma campaigns and programs [3,10]. Antistigma campaigns and programs illustrate hardships and accomplishments of people with mental illness as well as their potential for success and can target this message to members of society who occupy powerful systemic positions, such as healthcare and corporate leaders [10]. Contact between an array of people with mental illness and targeted groups can lead to 
reducing stigma and creating a more positive community for people with have mental illnesses [8]. Members of stigmatized groups can gain empowerment through openness about one's mental illness and attributing responsibility for stigma to society rather than self $[5,7]$.

As part of their 60th anniversary celebrations, the Canadian Mental Health Association (CMHA) Calgary Region launched "Now I'm Stronger," a public engagement and community relations campaign to drive interest in mental health and addictions and reduce stigma. CMHA Calgary used their mental health blog "Balance" to host and disseminate a diverse array of strengths-based conversations. Each day for the 60 days following the January 18, 2016 "Blue Monday" launch date, campaign participants authored their mental health experiences or resources using writing, poetry, videos, or photo voice. Blog entries centered on the question, "What Makes You Stronger?" thus comprise a collection of stories of recovery, strength and hope in the face of PTSD, depression, anxiety, bipolar, schizophrenia, and other mental health experiences.

The Now I'm Stronger campaign was grounded in the participatory action research principle of supporting populations to find their own solutions. In an endeavor to expand the reach of this campaign, CMHA Calgary partnered with a research team in the Community Rehabilitation and Disability Studies Program at the University of Calgary to treat the 60 Conversations as research data and generate and discuss themes in the data. This article comprises the collaborative analysis of participant stories and recommendations for how these stories can be used to inform mental health and addiction support. The purpose is twofold: 1 to showcase the range of strength and resources embedded in the 60 stories including in terms of how these can be used to inform policy and practice, and 2 - to critically examine the 60 stories in terms of the kinds of perspectives and experiences which are not represented, and a co-author who provides a 61st Conversation joins to illustrate and discuss ways to more fully capture and respond to diverse mental health perspectives.

\section{Methods}

\section{Narrative approach}

A narrative approach was used to generate then critically examine, themes in the 60 Conversations and as such, the authors treated individual stories as "consequential linking's" [11] of participant experiences. Using "analysis of narratives" [12] the authors generated themes from within and between participant stories. Then to deepen the ability to critically examine the themes, the first and second author worked with the third author, who lives with depression. Psychology professor and practitioner, Gail Hornstein, argues the benefit of researchers, or "experts by training," collaborating with people with lived experience with the studied phenomena, or "experts by experience" [13]. Our "expert by experience" co-author is a young woman named Sara, who immigrated to Canada from a country in North Africa as a young girl and lives with her mother and siblings in a low-income Muslim household. Sara, who is part of the personal network of the first author, was invited to join in authoring this paper because through initial rounds of analysis, the first two authors were struck by limitations of the sample, particularly in terms of cultural diversity. As the first two authors brainstormed efforts to address this, Sara stood out as ideally situated to help interrogate and round out the findings by bringing to bear the cultural, socioeconomic and gender particularities of her experience. Sara is not only open about her mental health journey, but also keen to use her experience to provide insight and support to others. Further, Sara is an accomplished writer with a fierce interest in pursuing a career in health services and Sara appreciates the competitive edge her authorship can lend her post-secondary plans. Sara's authorship contribution expands the analytic frame of reference and takes the form of Sara contributing, discussing and revising what this paper characterizes as a "61st Conversation." The sequential details are provided below about the processes of Sara's authorship as part of the data collection and analysis steps.

\section{Sample Recruitment and Data Collection}

Campaign participants were members of the Calgary community recruited in a number of ways. Of the 60 participants, 12are CMHA Calgary ambassadors chosen in October 2015 for the development of iMovies that illustrate experiences with addiction, serious and persistent mental illness, depression, and anxiety. Several other participants contacted CMHA Calgary requesting to share their stories after hearing early media coverage of the campaign. Remaining participants were recruited through snowball sampling initiated through an email call for story sharers in November 2015 that was distributed to CMHA Calgary staff, volunteers and affiliated agencies and acquaintances. Formalizing participation entailed emphasizing that participants were welcome to tell their stories in any way that was personally comfortable and meaningful. CMHA Calgary simply provided its blog, Balance, as a story-sharing platform and did not edit, direct, or choose the storytelling media. The 60 participants shared their stories in the forms of 16 videos/short films, 12 photo voice videos, 27 written posts, and five combined written and video posts.

\section{Data Analysis}

The first author led analysis of the three forms of narrative texts (i.e. written, spoken, and visual) comprising the 60 Conversations by first watching, reading, and/or listening to participant stories to develop general impressions $[14,15]$. Detailed notes were made to reflect topics, patterns, metaphors, tone, and imagery. Constant comparison practices were used to draw out themes within and between individual stories $[11,14]$ and the detailed notes were "coded" iteratively, with continual reference to participant stories and reflection on author interpretation of participants' written, spoken, and/or visual text. These themes were presented to the broader research team to refine decisions about how to represent participant stories and to identify and grapple with how to address the relative cultural homogeneity of the 60 Conversations, including discussing ways to engage the third author to advance the critical examination by comparing her own story to the themes generated. 


\section{The ethics of Sara's authorship}

The first author met with Sara to explain the work in this paper and invite her to co-author, including by sharing her story. Sara agreed, reviewed the findings, and began compiling her story focusing on mental health experiences she felt comfortable sharing and including how facets of her identity and social position influenced her story. The second author conferred with a professor of ethics to discuss the risks and benefits of authorship for Sara in light of her age. The first and second author then met with Sara to explicitly discuss the intended purpose and use of this article and the risks and benefits for her as an author. The first and second author presented Sara with authorship choices of 1- using her full name, 2- using a pseudonym or 3 - holding off submitting this article or publication until her 18th birthday. Further, authors underlined Sara's right to withdraw her authorship role any time until the date the article is submitted for publication. Sara asked questions and reiterated her conviction that she will find authorship beneficial. The authors followed up by email to confirm Sara's decision that she will use her full name. This paper compares Sara's story to the themes generated from the 60 Conversations and identify ways Sara's story reinforces and deepens themes from the 60 Conversations, as well as ways it illustrates distinct and underrepresented experiences related to the intersection of her identity, social position, and mental health.

\section{Findings}

Participants' mental health stories span the self, the community, and the society. In the "self" theme, participants described a dedication to self-knowing, self-care, and self-love as ways to "figure themselves out" and practice mental wellness. In the "community" theme, participants described the significance of reaching a place of sharing their mental health experiences and vulnerabilities towards breaking down stigma and connecting with others. Finally, in the "society" theme, participants described the shared responsibility of societal stakeholders in responding to and supporting community mental health needs with collective wisdom and resources. These themes are depicted in Figure 1. This paper describes each theme, concluding with

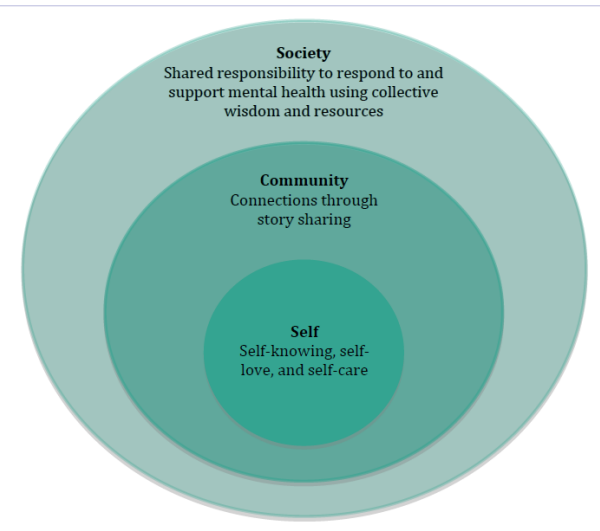

Figure 1: Components of "what makes me stronger" as described by participant campaign stories. components of Sara's story to highlight experiences Sara shares with 60 Conversation participants, and also to illustrate how Sara's mental illness is influenced by her culture, gender, religion and socioeconomic position.

\section{Self: Figuring oneself out}

Participants practiced mental wellness through introspection, self-expression, support from family and friends, and by striving to reach their potential. Mental health difficulties began in childhood and adolescence. Using photovoice, on day 41, recent University of Calgary graduate Dheny, shared:

I've struggled with my mental health since I was seven years old ... I had severe clinical depression, panic disorder, social anxiety, binge eating disorder, and agoraphobia ... I was angry because I had been dealing with mental illness for 13 years, despite only being 20 years old.

On day 45 Roger, who is father to two grown sons, and a counsellor at an addiction treatment center, reflected on his childhood using film:

I saw a lot of happy kids, and I just wasn't one of those ... By the time I was 14 years old I'd gone to three schools for grade nine, and I got more and more violent and more and more angry at my own life ... I was already drinking pretty much fulltime...

Participants described confronting their past, releasing emotions and finding purpose and self-understanding through yoga, running, music, painting, writing, spoken word, and comedy. On day 11, Jenny shared how written and spoken word became emotional outlets for loneliness, depression, and stress in the face of her parent's gambling addiction and two brothers being imprisoned during her adolescence:

Even in the present day, when I'm feeling my lows, and life doesn't seem tangible, writing my raw emotions and sharing them with the world lifts me up. It gives me purpose. It heals me. If I could share one thing that helps with my depression and anxiety it's this: find your expression, and let it heal you.

On day 52, Jane described in a short film how physical activity and the community at the fitness studio she owns have helped her mental health since losing her son traumatically a week before his 16th birthday:

We decided to have a month dedicated to mental health where we offered free classes for people to take a mental break because we know how physical health can help. So many people approached me personally and told me how happy they were that the studio was doing this thing with mental health how the studio was helping them so much through the community it created.

In a short film on day 60 , Simon described the importance of comedy in his life:

My relationship with depression is that we've known each other for a longtime. There's got to be something funny about this. If there's nothing funny about this, then this is way too tragic ... I don't think there's a way that I can measure comedy's importance in my life, because I don't think I would have a life without comedy. 
Participants discussed supportive family and friends who create safe space, advocate and support their mental health treatment plans, thus offering motivation and strength. Although participants discussed the difficulty of sharing mental health experiences, they emphasize that asking for help is an important part of gaining strength. Support from family and friends means participants knowing their own experience caused someone else's world to stop or change. After sharing his childhood experience of poverty, being bullied and navigating life as an immigrant, Alex closed his story on day 30 with an emphasis on friendships that supported him in childhood, and continue to support his mental health today:

Real strength comes from not being afraid of asking for help when it's needed. Real strength comes from standing up to inequality and unfairness in a respectful way. Real strength is being a friend to those who need it most. I am stronger because others stood up for me and cared.

On day 35 Mary, who lives with schizophrenia, shared the invaluable role of her support network:

Then I got God in my life in three different people: my best friend, my mother, and my caseload worker.

Participants put their mental health first and embrace their potential, however they wrestle with the limitations, stereotypes, and stigma imposed by society relative to their mental illness. Challenging negative images and working towards selfacceptance was a way for participants to reclaim their potential. Participants demonstrated the intense work required of the "self" to gain strength. Bryce used photovoice on day seven, to share his experience with bipolar disorder, and the importance of selfcare:

I was diagnosed bipolar as a teenager and I lived with the ever present awareness that, like some of my heroes, my illness would probably take me by 28 . That knowledge, as dark as it was, became the filter that I viewed by entire life through ... At 24 I hit bottom ... It was my time to choose life or for me to choose death ... I started taking steps to make my life more stable and I obsessively put my mental health first ... I started turning those darkest times and memories into optimistic music and art and that helps me understand myself and face those demons that had haunted me since I was a little kid.

Using photo voice on day 36, Katey described recovery after being sexually assaulted:

I was admitted to a four week-long outpatient program at the hospital. I forced myself to go every day ... Shortly after my discharge I came across this quote: 'then the day came when the risk to remain tight in the bud was greater than the risk it took to bloom.' I realized then that I had to get better for myself, for my family, and for my friends... I worked... to slowly replace my medication with meditation and conversation. And slowly, the good days outweighed the bad. I focused on each hour, which slowly evolved into each day. Mindfulness at its finest.

On day 39, Jennifer, a doctoral student at the University of Calgary, wrote about the invaluable potential and contributions of people who experience mental illness:
Accepting my story and making a conscious choice to create meaning in both the positive and negative chapters of my life has helped me move forward ... Yes, I can help others because of, not in spite of, experiencing mental illness.

\section{Sara's Story}

Sara echoed campaign participant messages of the value of introspection, self-expression and support from others in managing mental illness as she provided a vivid account of her struggles within a cultural context where mental illness is viewed as personal weakness. Sara wrote:

I use literature, academics, poetry, and journaling to understand my childhood and my experience. I have been open about my mental health journey, so I have learned to receive support, rather than experience mental illness in solitude.

I have been depressed for as long as I can remember. My earliest memories consist of me sobbing behind my dresser every night wondering why, although I was having fun, it felt like there was a dark ominous cloud looming over me, suffocating me.

Who caused me to feel this way? What did I do to deserve to feel so sad and disgusted with myself all the time? Why did I feel like the only way to make these feelings stop was if I harmed myself or die? These were the questions my seven-year-old self would contemplate; to this day these questions swirl around my mind.

I tried to find something to drown myself in, metaphorically, and I chose literature and academics. I would read to escape and keep my grades up to convince everyone I was alright. I had a limited knowledge of mental health, actually it didn't even seem to exist in my family and cultural background. If you felt sad you either deserved it, did something wrong, and/or didn't pray enough. There was no such thing as mental illness. So I began to blame myself, which in turn made my illness worse.

When I was 15 years old, every traumatic childhood memory resurfaced, and I don't actually know what happened. I started the year excited. Then one day I woke up and remembered that my parents were divorced. I remembered how 'my father' abused my mother and my siblings. How he would beat my mother and I would watch helplessly as she sobbed and bled, and I couldn't do a single thing. I remembered how I would be pushed down the stairs or beat with random objects, constantly wondering, why? I remembered how he controlled everything. I remembered how I was first sexually assaulted at seven, and then again at nine. Both times by the same neighborhood boy. But I couldn't tell anyone because I thought I deserved it, since I snuck out of the house in a skirt without wearing pants underneath. My mom always said that women who dress a certain way deserve anything that happens to them. And I believed what she said.

\section{Community: Reaching a place of sharing ones story and connecting through vulnerability}

Communal story sharing is the movement of a mental health experience from one's personal space to a space shared with the community, and is an important way participant to build 
community connections that strengthen them individually and reduce stigma. Making mental health a public conversation can illustrate the diverse and complex ways mental illness is experienced, reduce derogatory or limiting labels and corresponding stigma, and create a context for people to seek support and recovery.

On day15, Elizabeth used photovoice to share her 20-year journey with schizophrenia and her motivation for being public about her mental illness:

I want to erase the stigma. That's why we're [story sharing]. Some people say the stigma is worse than the illness, and the illness is pretty bad, so you can imagine how bad the stigma is. I've decided to be open about my illness ... Research came out that said the only way you beat stigma is by meeting someone who is doing well. At that point I thought the only way we're going to get rid of the stigma is if people like me are open about the illness, and say, 'it's okay.' It's okay to have a mental illness.

In a video on day 55, Krizia, organizer of [I'M]POSSIBLE community initiative, explained how grassroots and artistic efforts can raise mental health awareness:

[I'M]POSSIBLE [community initiative] was divided up into three stages. The first stage was about the stigma in mental health and how labels hurt. That stigma is what hinders people from reaching.

On day 58, Jessica wrote about the effects of her family never having discussed mental illness and the importance of her sharing her story now:

I remember a saying in our family, 'if you're going to suffer, suffer in silence.' It makes me cringe to write that today, because it is the farthest thing from what I now believe ... I want to help eliminate anything that could be preventing someone from getting the help or support they deserve. I want to remove the immense guilt, the shame, and the alienation that people who are dealing with a mental illness may be feeling... that should be the last thing someone who is sick should have to worry about. Sharing my story makes me feel incredibly vulnerable, but I feel that silence is much worse.

Communal story sharing made conversations about mental health more accessible to people who would otherwise continue suffering in silence. The experience of telling and listening to personal mental health stories inspired introspection, openness, resiliency, compassion, and understanding. Most important of story sharing was the sense of connectedness with people who have similar experiences. In a video on day 24 , Robb, a singer and speaker who works with youth, describes why conversation is necessary:

We've seen so many young people experience breakthroughs when they hear the tragic and inspiring stories of others... I don't want others to have to go through a near death experience like I did ... before they learn to live.

On day 25, a representative from the "Speak Your Mind
Project" explained why they offer a platform for Calgary youth to share their story:

The project is about putting a face onto the issue with the hopes that if people can see the individuals impacted by mental illness, we wouldn't feel uncomfortable talking about it more openly. It is about making an invisible issue very visible ... It is about lessening the silence because our conversation about mental health today can prevent the more serious consequences of mental illness tomorrow.

Simon (day 60) closes with this reflection on community:

I think that solidarity is one of the most beautiful things humans can give to each other. I'm suffering from the same things that you're suffering with, and we don't have to suffer alone and we don't have to suffer in silence.

\section{Sara's Story}

Sara underlines the value of communal story sharing, pointing out that although mental illness is not accepted in her community, sharing her story helps her feel connected with others and gives her a sense of being part of collectively breaking down stigma.

"Read to escape, write to conquer"- Unknown

Sharing my story has helped me in my journey to recovery. It has allowed me to connect with people who are experiencing similar pain, helped me feel less alone, and given me the courage to access the resources available for treating mental illness. When I share my story, I can feel my words chipping away at the boulder that is stigma. Every sliver gone is carving a clearer path to recovery for people with mental illness. The more we discuss mental health and illness, the more people want to learn, educate, and improve the resources and treatment approaches. When we share our stories, a ripple effect occurs. We inspire temerity, and sympathy blooms. By sharing stories to reduce stigma, we will help people with mental illness, and in turn our communities, thrive.

\section{Society: Using collective wisdom and resources and assuming collective responsibility}

Participants uphold diverse stakeholders, including government, education, healthcare, corporate and non-profit sectors, for their contributions resources, knowledge, and support as part of participants' mental health journeys. Participants also identify ways stakeholders could be more effective including through improved communication between agency services and resources, responding to the unique community and occupational mental health needs, addressing underlying causes of mental illness and addiction, destigmatizing mental health in the workplace, and restructuring health system responses to patients with mental health problems. Participant focus on stakeholders is a reminder of the collective responsibility to support community mental health, and provides an impetus to discuss, and improve, societal level responses to diverse needs.

Jennifer (day 39) described how schools and workplaces can foster positive mental health culture: 
A strong stigma remains in graduate school regarding struggling with mental health conditions; students feel pressure to do more, be more, and just power through. Joining the graduate mental health committee at the University of Calgary highlighted that others, like me, have struggled, fallen and persevered and want to make a difference in the mental health climate on campus.

On day 34, Charlotte described the support her daughter has received and emphasizes the value of peer support:

My daughter eventually accepted help after she had 28 psych ward admissions between 1997 and 2006. As I floundered, I was given help from many places. Doctors, nurses, mobile response team, but most of all, my help came from CMHA family peer support ... I was no longer alone.

Participants also discussed workplace support for mental wellness including Roger, Chief Constable of the Calgary Police Service, on day 38:

Police officers have one of the most stressful jobs in Canada. Every day, they face situations that require a careful balance between protecting citizens and serving the community ... Over the years we have built a comprehensive mental health program, which includes a wide range of resources for both our sworn and civilian members - from prevention to peer support and professional support.

On day 49, Callum, an advocate with CMHA Calgary, criticized short comings in health system response to people with mental health problems and envisions something better:

Jody had been picked up by police and taken to the hospital because of mental health ... Jody had sat with police and then by herself for 18 hours ... Unfortunately, many people will be turned away, deemed ineligible for support, even for those limited resources. Those not lucky enough to have family, friends, or an advocate can easily be forgotten. Help simply doesn't exist for everyone ... I'm not willing to accept the system the way it is anymore. Together we can create a community where everyone is welcome and not a process where you have to prove over and over again that you're worthy of help.

Judge James Ogle, on day 54, shared the successes of the Calgary Drug Treatment Court in addressing addiction and mental illness in the justice system:

Drug courts take a completely different approach [from traditional courts], and that's to fix the underlying problem. The most fulfilling part of my job in the drug court is to see the absolutely remarkable change in individuals from their first court appearance until their graduation day. It's just absolutely life changing alteration of who they are. The opposite of addiction is not sobriety, its connection.

\section{Sara's Story}

Sara reinforces ideas of the power, but also the limitations, of systems and services amidst her struggles and stressful family life. She recounts having been hospitalized three times for suicide attempts:
During these times, my family did not always accept the legitimacy of my depression and perceived my act as selfish. I am grateful for the services I have received, but I also feel lost and neglected by a system that I thought would support me when I was struggling:

Eventually, denying my illness stopped working, and I had enough. In my crowded school hallway, I swallowed all of my antidepressants and anti-anxiety medication. Logic kicked in a few minutes later, and I called my psychiatrist's office and I asked to see the principal. I woke up in a hospital, somewhat relieved but also angry at myself for telling anyone about my attempt.

I still don't know if I regret asking for help or not. I do regret waking up to a room full of people who loved me and having to explain everything. My stay was short and I was transferred to another hospital. Never did I imagine myself ending up in a psych ward! A psych ward! I met a lot of people that I keep in touch with today. But it was such a lonely experience. We weren't allowed to touch each other, discuss anything personal, and we had a strict daily schedule. It was an experience that definitely helped me stabilize but it also made me feel so alone. The longer I stayed there, the longer I thought about killing myself.

"You don't feel comfortable here, and you don't feel comfortable in your own house, so what's the point in living? Just die." I wanted that stupid voice to stop. I again asked, how could I possibly live like this? After I'd been there for a while and was granted a day pass, I attempted suicide again.

\section{Discussion}

Participants gave extensive evidence of the hardship of mental health combined with effort and dedication required to gain strength. Outlets for self-expression and introspection, a safe space to connect with their community, and personal, professional, and systemic support were sources of strength for participants. Commitments to "working on the self," fly in the face of the persistent stereotype of people with mental illnesses as lazy, unwilling to help themselves, and dependent on "the system." Instead, participants exposed stereotypes as lazy mindsets.

In the layers of participant stories, there are ways in which community and societal stakeholders can empower individual efforts and capacity. Community connections, often facilitated through grassroots initiatives, are an important space for individuals to find strength, belonging, and resources. These community spaces push back against interpersonal judgments, narrow and offensive media portrayals, and systemic stigma that trap individuals with mental illness in silence. Connections formed through community initiatives form the foundation for open and inclusive discussion of mental health by all societal stakeholders, and set standards of action in response to these discussions. Indeed, actively listening and responding to mental health stories is a community responsibility with systemic outcomes. Policymakers, educators, healthcare workers, business owners, corporate and non-profit leaders, among other professionals, have important privileges and responsibilities to 
translate personal and community mental health experiences into systemic change.

Like 60 Conversation participants, Sara depicts the value of self-expression, the importance of interpersonal support, a dedication to story sharing to reduce stigma, and the multifaceted nature of experiences with education and healthcare systems. Sara's co-authorship level of detail underlines the need to examine how gender, culture, religious background, and living in a low-income household and neighborhood influence mental health and access to support services. Sara further offered illustration of how these factors can be complicated by domestic violence and childhood sexual assault. Although Sara is now "safe" from abusers, she lives in an environment characterized by economic struggle of a minimum wage given her mother's educational qualifications not being recognized in Canada. Further, Sara must cope with her mother placing her at fault for her childhood sexual assault because of what Sara was wearing and doing when the assaults occurred. Thus many experiences contribute to Sara's depression, but the lack of acceptance of the legitimacy of mental illness in her family and cultural community constrains Sara's ability to manage her mental health and seek support.

Like Sara's story, some participant stories reflected aspects of identity or social position that influence their mental illness, such as sexual assault or other abuse, emigrating to Canada, and growing up in a low-income household and neighborhood. Fueled by the details of Sara's story, we can more fully consider the intersectionality of mental health and individual identities and communities, and take efforts to include and respond to minority or underrepresented stories. From and with and through Sara's story, we emphasize the need for diverse representation in educational and stigma reduction campaigns to increase visibility of minority communities such that stakeholders can better understand and respond to diverse experiences and needs of individuals and communities.

Below are four recommendations for mental health stakeholders in Calgary:

1. Leverage existing platforms to be inclusive of diverse mental health stories and experiences which can be shared without judgment.

2. Design, implement, and evaluate/improve arts and physical activity programming and resources that offer equitable access to members of the community through the healthcare and education systems, universities, workplaces, community centers, libraries and parks.

3. Redouble efforts to challenge mental health stigma by carving opportunities for mainstream discussion of mental health, by designing and implementing, evaluating/ improving policies for supportive work cultures, and by promoting appropriate and accessible resources.

4. Network existing organizations, grassroots initiatives, and services to individuals can more readily become aware of, and connected to, culturally informed resources and supports in their community.

\section{Conclusion}

Overall, the 60 Conversations showcase a breadth and depth of lived experience and wisdom and reinforce our collective responsibility to use this wisdom to address mental health needs through interpersonal relationships, community initiatives, and policy. Through analysis of these stories, we hope readers who experience mental illness can identify themselves. And we hope further that our analysis resonates with academics and professionals working with and for people who have mental illnesses and illuminate academic and professional responses. In this paper, and other campaigns challenging stigma, words give readers fortitude to persevere and allow entrance to a community where their experience is a source of belonging, rather than isolation. The 61 voices represented here collectively erode stigma to carve a path for the 62 nd Conversation.

\section{Acknowledgement}

We thank the contributions and commend the strength of "Now I'm Stronger" participants for sharing their stories and experiences with the public, making this research possible, and contributing to stigma reduction.

\section{References}

1. Herek GM. Sexual prejudice. In: Handbook of Prejudice, Stereotyping, and Discrimination. Nelson TD, editor. Psychology Press: New York, NY. 2009.

2. Herek G. Hate crimes and stigma-related experiences among sexual minority adults in the United States: prevalence estimates from a national probability sample. J Interpers Violence. 2009;24(1):54-74. doi: $10.1177 / 0886260508316477$.

3. Campellone T. Treating the cause, not the symptoms, of mental illness stigma. The Lancet Psychiatry. 2014;1(2):96-97.

4. SSzeto A, Luong D, Dobson KS. Does labeling matter? An examination of attitudes and perceptions of labels for mental disorders. Soc Psychiatry Psychiatr Epidemiol. 2013;48(4):659-71. doi: 10.1007/ s00127-012-0532-7.

5. Frost D. Social stigma and its consequences for the socially stigmatized. Social and Personality Psychology Compass. 2011;5(11):824-39.

6. Hutcheon EJ. "Cripping" resilience: generating new vocabularies of resilience from narratives of post-secondary students who experience disability. In: Faculty of Graduate Studies. University of Calgary: Calgary, AB. 2015.

7. Corrigan PW, Rao D. On the self-stigma of mental illness: stages, disclosure, and strategies for change. Canadian Journal of Psychiatry. 2012;57(8):464-49.

8. Henderson C, Evans-Lacko S, Thornicroft G. Mental illness stigma, help seeking, and public health programs. Am J Public Health. 2013;103(5):777-80. doi: 10.2105/AJPH.2012.301056.

9. Knaak S, Patten S, Ungar T. Mental illness stigma as a quality-of-care problem. Lancet Psychiatry. 2015;2(10):863-4. doi: 10.1016/S22150366(15)00382-X.

10. Corrigan PW. Strategic stigma change (SSC): five principles for social marketing campaigns to reduce stigma. Psychiatr Serv. 2011;62(8):824-6. doi: 10.1176/appi.ps.62.8.824.

11. Lal S, Suto M, Ungar M. Examining the potential of combining the methods of grounded theory and narrative inquiry: a comparative analysis. The Qualitative Report. 2012;17(21):1-22. 
12. Creswell JW. Research design: Qualitative, quantitative and mixed methods approaches. Thousand Oaks, CA: Sage Publications Inc. 2014.

13. Hornstein G. Practice sharing: teaching mental health using first person accounts of madness. In: The Higher Education Academy of Psychology. Newsletter: Psychology Network. 2010.
14. Keats P. Multiple text analysis in narrative research: visual, written, and spoken stories of experience. Qualitative Research. 2009;9(2):181-95

15. Lieblich A, Tuval-Mashiach R, Zilber T. Narrative research: reading, analysis, and interpretation. Sage Publications, Inc: Thousand Oaks, CA. 1998. 